\title{
Competing societal and ecological demands for groundwater: boundary judgments and convergence mechanisms in the Netherlands
}

\author{
Valentina Dinica
}

Received: 5 July 2013/ Accepted: 24 September 2013/Published online: 4 October 2013

(C) The Author(s) 2013. This article is published with open access at Springerlink.com

\begin{abstract}
Conflicts between human demands for clean water and terrestrial ecosystems' needs for water are increasing. Such conflicts are stronger in the case of groundwater, as one of the cleanest forms of drinking water, and are expected to increase in frequency, in the context of population growth and climatic changes. This paper argues that behavioral approaches are essential not only toward understanding how socio-ecological conflicts emerge, but also how they could be overcome. A theoretical the framework is proposed, which suggests that the behaviors/actions of actors who sustain such conflicts can be understood by examining their 'boundary judgments' regarding natural resources and sustainability, in interaction with their powers/resources to implement the preferred behaviors. The concept of boundary judgements is rarely used in investigating sustainability conflicts. This concept is operationalized in relation to nature-society conflicts and applied empirically to illuminate the conflict in a case study from the Netherlands. Further, the theoretical framework suggests a parsimonious, yet comprehensive, typology of mechanisms that can be used to change/'converge' the behaviors and actions of the actors contributing to the problem, toward conflict closure. These are referred to as convergence mechanisms and can be persuasive, enabling or constraining. The paper concludes with reflections on the practical usefulness of the framework and concretes suggestions for further research, drawing on these convergence mechanisms and their interactions with boundary judgments on natural resources and sustainability.
\end{abstract}

Keywords Groundwater · Nature $\cdot$ Conflicts · Sustainability ·

Boundary judgments $\cdot$ Behavioral change

\section{Introduction}

Groundwater is the most desirable drinking water source, because it is cleaner and cheaper to process. In the Netherlands, around two-thirds of people are supplied with drinking

V. Dinica $(\bowtie)$

School of Government, Victoria University of Wellington, Wellington, New Zealand

e-mail: valentina.dinica@vuw.ac.nz 
water from deep or shallow aquifers. ${ }^{1}$ Agriculture and various industrial sectors also extract groundwater. However, the survival and quality of many terrestrial ecosystems depends on groundwater. Wetlands are more sensitive than other ecosystems, as they require high and stable groundwater levels in shallow aquifers.

Wetlands, like the Wierdense-Veld ${ }^{2}$ in the Eastern Dutch Province of Overijssel, were drained for centuries, for agricultural proposes. This particular wetland escaped full irreversible conversion, and the small left-over area of 420 ha, in the Wierden municipality, started to be legally protected in 1968 when the non-governmental organization Landscape Overijssel (LO) became its manager (Arcadis 2008, 15). By 2000, the Wierdense-Veld was already protected under the national legal system of 'key ecological structures' (KES), for which the Provincial Government of Overijssel had implementation responsibilities. The Wierdense-Veld has continued to be affected, nevertheless, by significant dehydration, mainly due to agricultural practices and the exploitation of the shallow aquifer, lying partly below it, for drinking water production (KIWA 2007). The legal regime has been so far unable to reverse this process, during 40 years of nature protection (Dinica 2009).

The case discussed in this paper is representative for the Netherlands and other densely populated countries and regions, where nature areas often border lands with conflicting demands on the required groundwater tables. Ideally, there should be 'buffer zones,' allowing groundwater levels to raise and fall, according to ecological and societal demands. However, historical developments in the absence of ecological insights resulted in numerous such situations of 'incompatible neighbors,' in the context of land scarcity. This is also the case with Wierdense-Veld, which borders the growing urban areas of the Wierden and Hellendoorn municipalities, and farms practicing intensive agriculture; most of these areas require low groundwater tables (Dinica 2009).

Such conflicts between ecological and societal requirements are undesirable, but how can they be tackled? When ecological systems are relatively 'simple and replicable,' not harboring endangered species and habitats, their destruction for societal purposes can be compensated through nature development elsewhere. This is often allowed under national, even European, legislation. However, wetlands are unique historical ecosystems, formed during the Ice Age through glacial retreat. They enable the survival of rare fauna and flora and provide significant ecosystem services for societies, including biodiversity conservation, carbon and water storage. Wierdense-Veld cannot be sacrificed anymore, as it is protected under the Dutch KES legislation. Moreover, the European Union adopted in 1972 a Directive for Birds' protection, complemented in 1992 with a Habitat Protection Directive. The later was transposed into Dutch legislation in 1998. The implementation of the two directives is connected in practice through the nomination of certain areas as 'Natura-2000' sites. These should form a well-connected network of valuable ecosystems throughout the European Union countries. In 1998, the Minister for Nature, Agriculture and Fisheries decided to list Wierdense-Veld as a candidate for Natura-2000 denomination. Consequently, given the historical-ecological value of this wetland and the possibility of a strengthened legal protection, the competing demands on groundwater between nature and society can only be addressed through the behavioral change of those contributing to the lowering of groundwater tables.

\footnotetext{
${ }_{1}$ From: http://www.rijksoverheid.nl/onderwerpen/waterkwaliteit/vraag-en-antwoord/wat-is-drinkwater.html.

2 A map of the area can be found at: http://www.landschapoverijssel.nl/wierdense-veld.
} 


\section{A behavioral approach to the study of natural resource conflicts}

'Behavioral changes' refer (in this context of conflicts regarding natural resources usegroundwater, and impacts - nature areas) to changes in economic activities, businesses practices, nature conservation practices or even policy designs and strategies, by the individual actors and organizations/companies responsible for an unsustainable situation. While social-psychology studies behavior as a feature of individuals, this concept may be used (metaphorically) in relation to organizations, when investigating their interaction with other actors in society and the consequences of their actions/decisions for ecological systems. Just like individuals, organizations are guided in their activities and interactions by motivational factors, such as a set of shared values among their employees/members and leaders, or principles, objectives and interests that are agreed upon internally and communicated/ defended externally by all those representing them (be them companies, city councils, ministries, NGOs, governments). 'Organizational behaviors' are therefore referred to metaphorically in this paper to refer to policy choices, technology choices, resource use choices and management practices. Such actions are informed by the knowledge available to staff and management (Sabatier and Jenkins-Smith 1999; Bressers 2006; Spillane et al. 2002). The study of natural resource conflicts should, hence, ideally include an examination of the motivational and knowledge-related factors affecting actors' behavioral/action preferences.

A relatively recent, and seldom used, concept that incorporates such factors is that of 'boundary judgments.' The most significant theoretical contribution on the 'boundary critique' has come from the Swiss social scientist and philosopher Werner Ulrich, as part of his theory on Critical Systems Heuristics (Ulrich 1987). According to Ulrich ${ }^{3}(2002,41)$, "both the meaning and the validity of professional propositions always depend on boundary judgments as to what "facts" (observations) and "norms" (valuation standards) are to be considered relevant and what others are to be left out or considered less important. Such boundary judgments are constitutive of the reference systems to which refer all our claims to knowledge or rationality, in professional practice as well as in everyday life.'

There is currently very limited published literature that applies the concept of boundary judgments at all (see here Bressers and Lulofs 2010; Warner et al. 2010, as the most relevant publications for the focus of this paper), let alone in Ulrich's conceptualization, which has been mainly carried out by the author and collaborators (see, e.g., Ulrich and Reynolds 2010). 'CSH uses a set of 12 questions to make explicit the everyday judgements on which we rely (consciously or not) to understand situations and to design systems for improving them' (Ulrich and Reynolds 2010, 244). Ulrich designed CSH and the twelve questions with the aim of supporting 'reflective practice.' The 'CSH can support professional interventions in two general ways: It can help us to evaluate an intervention, or it can inform the methodologies used for intervention' (Ulrich and Reynolds 2010, 248).

This paper aims to understand the factors and mechanisms affecting the prospects for conflict resolution, for the case of competing societal and nature demands on water resources. This analysis is ex-post, while CSH and its operationalizing questions were intended for ex-ante or simultaneous action research. Nevertheless, for the purpose of this paper, understanding boundary judgments is important, because they affect how actors behave. Unveiling the way actors bound the problems they are confronted with, may help to gauge the likely effectiveness of mechanisms and tools aiming to encourage learning and motivational changes, toward behavioral/action change and conflict closure. Consequently, this paper borrows Ulrich's term of boundary judgments, uses it in the spirit of the

\footnotetext{
${ }^{3}$ See Ulrich's Home Page for publications list http://www.wulrich.com/downloads.html.
} 
above definition, but suggests a parsimonious operationalization that serves the purpose of this paper.

Several research questions emerge when studying the behavior of actors involved in natural resource conflicts:

1. How do the boundary judgments on natural resources, applied to justify behavioral/ action preferences, emerge? How are ideas, regarding what is relevant and what is to be left out, shaped?

2. How can such boundary judgments be altered through multi-actor interactions?

In addition, one needs to consider that behaviors and actions are not entirely and always driven by boundary judgments. Whether they act in private or official capacity, actors have to respect formal and informal rules (often there are prescribed competences, responsibilities, accountabilities, discretion scopes); actors have various levels and qualities of resources available (material and non-material) to make decisions and implement them. Consequently, the third question that emerges is:

3. How to generate 'convergence' among conflicting actors toward conflict closure?

'Convergence mechanisms' is the collective term used in this paper for all kinds of mechanisms that may help change the actions of actors contributing to a resource conflict, with positive sustainability outcomes. This section continues by providing some reflections on these questions, captured by the theoretical framework shown in Fig. 1, which will be used to guide the empirical explorations through the rest of the paper.

A key proposition of this framework is that actors' boundary judgments regarding (the use and quality of) natural resources draw most often on conceptualizations and

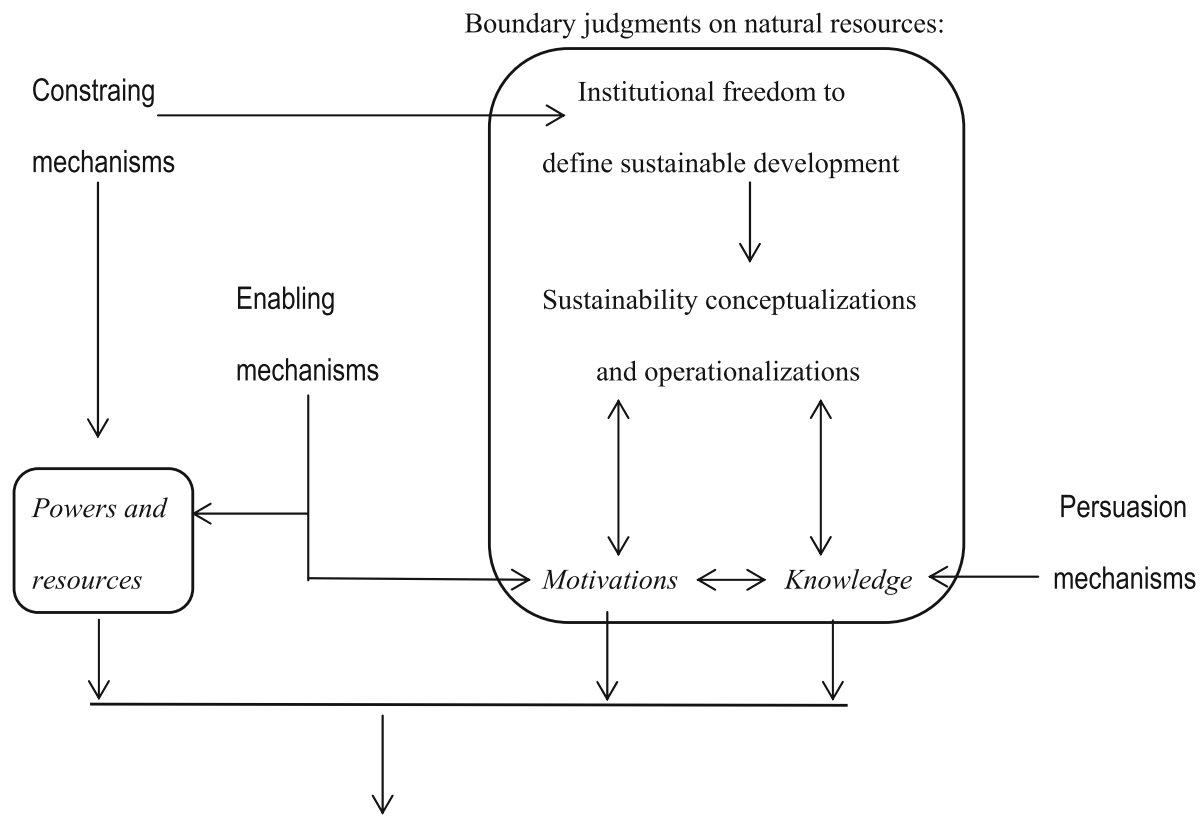

behavioural/action change: likely / unlikely

Fig. 1 Boundary judgments on natural resources and mechanisms for convergence toward conflict closure 
operationalizations of sustainable development, which may vary widely. The use of natural resources, such as waters, fossil fuels and other energy resources, minerals, biodiversity, and so on, has consequences for the reserves/depletability of those resources. But their use is also accompanied by various negative environmental, social and economic impacts. Indeed, the need for the long-term availability and quality of certain types of natural resources is a key point of difference between conceptualizations of 'weak' and 'strong sustainability' (Solow 1986; Cabeza-Gutés 1996; van der Bergh et al. 2007). Without reproducing the extensive literature of relevance here is that weak sustainability claims natural capital may be depleted, as long as it is replaceable by man-made capital, or substitutes can be generated through human interventions. E.g., nature does not have an intrinsic value, and its destruction may be compensated through nature development elsewhere or through man-made capital for function reproduction.

The concept of strong sustainability presents challenges because it is holistic, aiming to harmonize ecosystems' and societal evolution across many dimensions, governance levels, spatial scales, resource types, temporal scales, etc. It also implies new roles and responsibilities for basically all kinds as societal actors. However, not all actors embrace holistic conceptualizations, because of motivational factors and/or knowledge-related factors. Therefore, conflicting actors are likely to emphasize sustainability aspects differently. As Fig. 1 suggests, an actor's motivations and knowledge base are connected; they typically shape each other. Psychology has long established that acquiring new knowledge, or new ways or interpreting known information, may also change an individual's motivation to act, hence his propensity for behavioral change (Gazzaniga and Heatherton 2003; Dillard and Pfau 2002; Seiter and Gass 2010). As organizational actions are driven by people, similar arguments may be made for changes in organizational actions in interactions with other societal actors.

The above-mentioned processes will be influenced by the institutional freedom actors have in conceptualizing/operationalizing sustainable development in their policies and actions. E.g., environmental non-governmental organizations, like Landscape Overijssel (LO) which is the owner and legal manager of the Wierdense-Veld, have a low institutional freedom, having to observe ecological and recreational responsibilities set in their organizational statute and the legal framework. Moreover, actors may also enjoy various degrees of freedom in operationalizing the regulation-specified or self-selected sustainability aspects on which they should concentrate. Consequently, four key (groups of) factors will be considered in this paper for further empirical investigations, as shaping the actors' boundary judgments on natural resources use: knowledge bases (not only the raw facts and data available, but also their interpretation, as underpinned by beliefs and attitudes); motivations (interests/objectives, core values, see Sabatier and Jenkins-Smith 1999); conceptualization and operationalization of sustainable development and the institutional freedom available for this.

The second question raised asks: how can boundary judgments be altered through multiactor interactions? The most obvious mechanism is that of learning. The 'sustainability science' has emerged and matured since the launch of the sustainable development concept in early 1970s. Relationships between human activities, ecosystems, natural resources and the global atmosphere are currently better understood. However, the available knowledge is not uniformly distributed across stakeholders. This makes learning mechanisms prime candidates for 'convergence mechanisms.' This paper proposes to use a term often used in psychology, namely persuasion, in acknowledgement of the interactions between motivations and knowledge bases. Psychologists investigate the role of persuasion in individuals' behavioral changes (Allen and Preiss 1998; Cialdini 2007; DellaVigna and Gentzko 
2010). Persuasion is defined as 'the active and conscious effort to change attitudes through the transmission of a message' (Gazzaniga and Heatherton 2003, 435).

The psychology literature largely accepts, nevertheless, that behavior cannot always be inferred from the exclusive study of motivations and information (Gazzaniga and Heatherton 2003; Kahneman 2012; Dillard and Pfau 2002; Seiter and Gass 2010). The structure of the situation in which the individual acts, the (potential) behavior of other actors present in the operation environment, the expectations regarding how other actors would evaluate his behavior, the material conditions in the action environment-all affect the behavioral choice of an individual. In addition, informal and formal rules (Ostrom 1987) and rules are put in place to constrain certain undesirable individual behaviors and organizational actions or to stimulate desirable ones. Lockton et al. (2009) have recently developed a theory, referred to as the 'Design with Intend Method,' which aims to generate socially desirable (e.g., environmentally friendly) changes in individuals behaviors and organizational actions. They differentiate between three (classes of) mechanisms:

- 'enabling desirable behavior,' by making it easier for the user to engage in it as compared to the alternatives;

- motivating behavioral change 'by educating, incentivizing and changing attitudes,' and

- constraining mechanisms, which basically make the undesirable behavioral alternatives 'difficult or impossible' (Lockton et al. 2009, 3).

This paper will adopt this typology, but will refer to the second category as 'persuasion mechanisms,' for the reasons explained above. Moreover, the term persuasion has already penetrated the language of national and international policy makers. The typology is parsimonious, yet comprehensive. Its categories capture the spirit of most behavioral change mechanisms currently coined differently in the literature, e.g., 'nudging' (which sometimes works through 'enabling' and other times through 'persuasion'); or 'coercive mechanisms'; or 'bargaining'/'negotiation,' which may have consequences for actors motivations and/or resources/power (Bressers 2006; Klok 1991).

The arrows in Fig. 1 indicate that all three mechanisms may influence boundary judgments on natural resources. Constraining mechanisms, such as legal specifications or organizational statutes, may offer stakeholders various degrees of freedom to conceptualize/operationalize sustainability. In this case, behavioral influences operate indirectly. However, constraining interventions may also affect behaviors directly, when they affect actors' resources (e.g., the application of fines, disclosure of undesirable behaviors to consumers/voters) or powers (legal prescriptions against certain behaviors). Actors' resources/powers are often distinguished as significant characteristic in policy studies, especially by academics studying implementation processes (when conflicts frequently emerge; see Bressers 2006; Klok 1991). Enabling mechanisms may also be conceived so as to affect actors directly, but positively, by offering financial inducements or non-material stimuli for behavioral/action change. It is possible that actors experience positive attitudes, which may even reshuffle their hierarchy of values (experiencing, therefore, motivational changes when such inducements/facilities become available). Therefore, enabling mechanisms might produce both direct behavioral/action changes and indirect ones, through changes in the boundary judgments regarding natural resources.

Consequently, if behavioral/action changes for the resolution of resource-related conflicts may be induced through three classes of convergence mechanisms, what is the interplay between them, and when should we expect behavioral/action change? This last question has been hardly investigated in policy studies, while there are some insights of interest from psychology, which need to be further considered to generate more specific knowledge on 
resource conflicts. E.g., psychology has mostly produced and tested theories on the effectiveness of various persuasion approaches and strategies (e.g., the Elaboration Likelihood Model, see Seiter and Gass 2010; or Cognitive Dissonance Theory, the Theory of Reasoned Action, and Language Expectancy Theory in Dillard and Pfau 2002), noting that persuasion messages are most likely to be attended in the shadow of constraining mechanisms, likewise for enabling mechanisms. It would be valuable to continue advancing knowledge along this track, through more refined insights into the workings of these three mechanisms for conflicts regarding natural resources. This paper aims to contribute toward this goal, by means of the framework of inquiry sketched in Fig. 1 and explained in this section, as well as an illustration of its usefulness for knowledge creation through an empirical application. The case study looks at the boundary judgments and the impacts of convergence mechanisms for the actors contributing most significantly to the dehydration of the Wierdense-Veld: the provincial drinking water production company Vitens (formerly known as Water Management Corporation Overijssel, WMO) and farmers.

\section{Background to the case study and the research methodology}

The wetlands between the municipalities of Wierden and Hellendoorn, called the Wierdense-Veld, have been affected by dehydration for more than 100 years. Key types of habitats were thriving there once, which Natura-2000 legislation aims to restore: dry heath, wet heath, active peat and peat. By 2007, active peat ${ }^{4}$ and peat habitats were basically absent, while the expected timespan for peat restoration was 100-150 years (PCO 2007, 78); dry and wet heath habitats were under significant stress (KIWA 2007, 5-8). The Natura-2000 legislation envisages for this wetland the recovery of the former three habitats as 'primary goals,' while peat restoration is a 'complementary goal' for which national authorities are not accountable to European authorities. Nevertheless, the Dutch Nature Ministry prioritizes peat habitats because they are rare. The Netherlands and Germany are the only European countries where these habitats are historical, culturally significant and still feasible (Arcadis 2008, 7). This was the Ministry's main reason for including Wierdense-Veld in the Natura-2000 list.

Dehydration is most severe on the eastern side of the reserve, which borders many farms and the Wierden town a bit further to the east, as shown in the area sketch, in Fig. 2. Municipal and industrial extraction activities on the western side are under the competence of the Hellendoorn municipality. They also contribute to dehydration. However, due to paper size constraints, and given their smaller contribution to groundwater table lowering (less than $20 \mathrm{~cm}$; Interviewee 2, 2009), this case study will only focus on the contributors from the eastern side of the reserve.

An independent expert study (TNO 1994) indicated that the groundwater table of the shallow aquifer below the wetlands lowered by $120 \mathrm{~cm}$ over the past 100 years. It also estimated the lifting of groundwater tables if key stakeholders implemented adequate measures. Vitens' reduction in groundwater extraction at Pump 1 by 4 million cubic meters per year $\left(\mathrm{Mm}^{3} /\right.$ year) could lift the groundwater table by up to $20 \mathrm{~cm}$. A further lifting of $10 \mathrm{~cm}$ is possible if Vitens agrees to stop extracting groundwater at its Nijverdal pumps. The behavioral changes of all farmers located to the east of Wierdense-Veld are expected

\footnotetext{
4 Active peat means vegetation that is supportive of peat habitat formation, according to the "Interpretation Manual of European Union Habitats" (2007, European Commission Directorate Environment), retrieved 2 July 2012 from http://ec.europa.eu/environment/nature/legislation/habitatsdirective/docs/2007_07_im.pdf.
} 
Farms

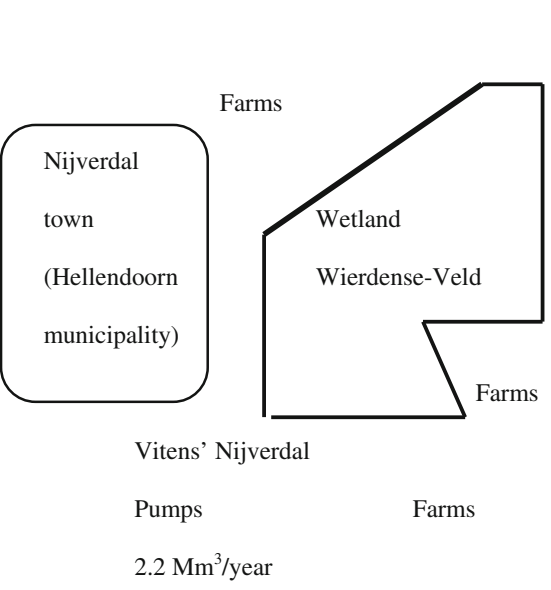

Farms

Farms

Farms

Vitens Hoge Texel pumps

$2.2 \mathrm{Mm}^{3} /$ year

Farms Farms

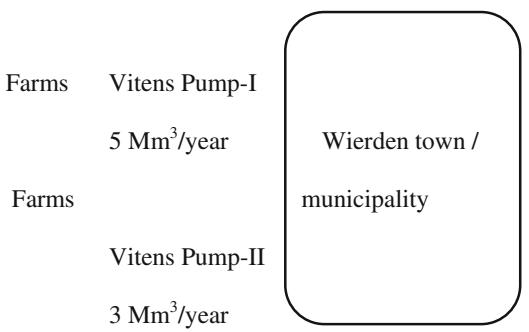

Fig. 2 A sketch of the area around the Wierdense-Veld wetland (based on KIWA 2007, 3)

to lead to table level increases of $40 \mathrm{~cm}$ (Interviewee 2, 2009). Landscape Overijssel acknowledged its role in implementing certain ecological-infrastructural measures to help increase the table level by further $10 \mathrm{~cm}$ (Interviewee 2, 2009; these are listed in Arcadis 2008, 38). The local Water Board Regge and Dinkel (WRD), a historical multi-stakeholder politically elected public authority, offered from the start to help farmers implement the needed measures at farm level (Interviewees 1, 2009). Furthermore, WRD played a key role in a 'persuasive mechanism,' to influence the behaviors of farmers and Vitens.

\subsection{Research methodology}

The research methodology used in this paper is summarized in Table 1, which shows the research techniques used to gather information for the variables included in the theoretical framework (Fig. 1), per actor (type) investigated for behavioral/action change. The techniques are listed in the order of their impact on the research findings, in terms of the informational richness offered by the respective sources. The following research techniques were used (Dinica 2009):

a. analysis of official documents: Vitens' company policy; policy papers/strategies and management plans of the Provincial Council of Overijssel (PCO, as Vitens' permit giver); texts from European and national legislation;

b. analysis of official statements: from the Nature Ministry/Minister, PCO and Vitens, official letters between stakeholders, and Vitens' Newsletters;

c. analysis of published work of academics: consultancy researchers, public sector and private company analysts;

d. private interviews (face-to-face, $90 \mathrm{~min}$, confidential) with representatives from Waterboard Regge and Dinkel (Interviewees 1 and 4), Landscape Overijssel (Interviewee 2) and Vitens (Interviewee 3). A detailed interview schedule was used, with open and closed questions. Interviews were recorded with prior consent and transcribed for analysis. Several representatives of PCO were invited for interview, but 
Table 1 Research methods used for the empirical analysis of the framework's variables

\begin{tabular}{lll}
\hline Actor & Framework variable & Research method \\
\hline Vitens & $\begin{array}{l}\text { Sustainability definitions and the applicable } \\
\text { institutional freedom } \\
\text { Motivations, cognitions }\end{array}$ & (a), (d), (c) \\
& Convergence mechanisms & (d), (c) \\
& Behavioral outcome by 2012 & (c), (b), (d), (a) \\
& Sustainability definitions and the applicable & (b), (c) \\
& institutional freedom & (a), (c) \\
Farmers & Motivations, cognitions & (c), (d) \\
& Convergence mechanisms & (c), (b), (d), (a) \\
& Behavioral outcome by 2012 & (c)
\end{tabular}

they declined, recommending the analysis of the official PCO documents and published literature. 5

In relation to farmers, empirical information was extracted from several publications that were found to contain rich and very relevant references to boundary judgments and the frameworks' variables: Owens (2008), Arcadis (2008) and PCO (2007). ${ }^{6}$ The findings on farmers with regard to research question (1) and, to some extent, (2), rely on indirect sources. The analysis of farmers' behaviors offers valuable additional lessons that can be drawn regarding research questions (2) and (3) and guidance for a research agenda using the theoretical framework proposed in this paper.

\section{Convergence mechanisms, boundary judgments and behavioral/action changes to combat dehydration at Wierdense-Veld}

All stakeholders have been long aware of the dehydration problem at Wierdense-Veld. Vitens' knowledge of the details and magnitude of its impacts improved in 1990, through a self-commissioned ecological study (Owens 2008, 99). However, it has continued its operations at all pumps shown in Fig. 2 for long, invoking its groundwater extraction permit from PCO. The year 2000 (the start of the period investigated in this case study) was important for several reasons. These are explained below, while convergence mechanisms are introduced.

\footnotetext{
${ }^{5}$ PCO is politically elected by citizens in the province. While, often, politicians from the entire political spectrum are PCO members, right-wing/conservative politicians traditionally dominate PCO, given that agriculture is the main economic sector of Overijssel. While the paper refers to PCO, as shorthand, what is meant is the political party or coalition dominating PCO at the time referred to in the analysis.

${ }^{6}$ Owens worked on her doctoral thesis under the author's guidance as Second Supervisor. She interviewed one farmer involved in one persuasive mechanism, with regard to his motivations and knowledge bases relevant for Wierdense-Veld's restoration. Owens tested Hans Bressers' Contextual Interaction Theory (2006), incorporating these two variables. Her findings were triangulated with perceptions on farmers' motivation and knowledge by the four interviewees and with relevant analyses reported in Arcadis (2008) and PCO (2007).
} 


\subsection{Convergence mechanisms}

The European Water Framework Directive 2000/60/EC was transposed in Dutch legislation in 2000. Articles 6, 8, 11.3 and $11.7-8$ require states to monitor the water volumes in aquifers feeding Natura-2000 areas, report them, design protection programs for such areas (by 2009) and implement them (by 2012). These provisions aim to ensure that Natura-2000 objectives are met. As the Water Framework Directive can be enforced through juridical authorities, it has the potential of becoming a 'constraining mechanism' for Vitens, after 2009-2012.

The Nature Minister pre-announced Wierdense-Veld's listing in 1998. However, it could only be definitively registered in Brussels in late 2009, because of opposition from some PCO members lobbying right-wing politicians in the Dutch Parliament (Verburg 2008). Therefore, up to 2009, there was a period of uncertainty for both Vitens and farmers, which is important for the investigation of the effectiveness of any persuasion mechanisms identified. Starting with 2009, Vitens and farmers have to consider LO's and Nature Minister's option to resort to this (second, for Vitens) European constraining mechanism, should their practical operations prove to compromise the three primary Natura-2000 goals.

Further, in 2000, multi-stakeholder regional processes started countrywide under the name 'The Desired Regime for the Use of Groundwater and Surface Waters' (GGOR, in Dutch abbreviation). One such process was led by WRD for the eastern side of WierdenseVeld: GGOR-East. These processes were meant to help implement the 2000 Water Framework Directive. This is considered here a 'persuasion mechanism,' because it formed an interaction arena (Ostrom 1987) where actors could interact to explore problems, values, priorities, potential solutions and discuss any relevant research studies, evidence and new insights. All these aspects belong to the spheres of motivations and knowledge bases and may influence the boundary judgments on the use of, and impacts on, natural resources. The process aims to be constructive and consensus oriented. In such processes, each actor will attempt to persuade others regarding the desirability of its behaviors or promoted objectives, and in its turn, each actor will be exposed to the persuasive messages of others. WRD facilitated meetings with numerous stakeholders, including LO, 22 farmers, Vitens, WRD, PCO and the municipalities of Wierden and Nijverdal. WRD asked the consultancy Information for Agriculture (DLV) to carry out studies and present technical measures for the lifting of groundwater tables at Wierdense-Veld (presented in DLV 2002). These were discussed together with other measures proposed in a key previous study commissioned by PCO (TNO 1994), and another independent report tabled in 2005 (Tomassen et al. 2005).

Interestingly, 2000 was also the year when the Wierden municipality approached Vitens with a request to close down part of its Pump-I production (about $2 \mathrm{Mm}^{3} /$ year; Fig. 2), because it planned to build the A35 road close-by. Wierden authorities informed Vitens, additionally, that for the sustainable development of Wierden, a compact expansion of housing is most appropriate. New land was needed west of Wierden and some extraction sites at Pump-I formed an obstacle. Additionally, Wierden's industrial estates were already polluting groundwater at some sites of Pump-I, while housing areas posed contamination risks through sewage infrastructure leakages (TAUW 2009, 21-28). Hence, the road plan, high pollution risks and city expansion plans became serious, albeit physical, 'constraining mechanisms' for Vitens toward changing its operations at Pump 1, by closing-down $2 \mathrm{Mm}^{3} /$ year of extraction. However, while this change may lift groundwater tables by $10 \mathrm{~cm}$ at Wierdense-Veld (Interviewee 2, 2009), it is worth noting that Wierden authorities 
opposed Natura-2000 listing and supported Vitens' and PCO's strong preference for using groundwater for drinking water production, rather than surface water (Interviewee 2, 2009). PCO and municipal authorities are share owners in the publicly owned company Vitens. Some PCO members made many attempts not only to block Wierdense-Veld's listing as Natura-2000, but also to reverse its definitive nomination, ${ }^{7}$ after 2009.

\subsection{Vitens' boundary judgments and the consequences of convergence mechanisms}

Vitens' conceptualization of sustainable development is restricted to the production of drinking water, which has to satisfy five key criteria: minimize production costs; safeguard human health; ensure security of supply; be environmentally friendly; and 'have acceptable impacts in the surrounding areas (water systems, environment and landscapes' (Vitens 2002 , 28). If a combination of water resources and technology at a site satisfies these criteria, extraction activities are viewed as locally sustainable. The company aims to contribute to sustainable development, by managing all its sites sustainably, and compensating neighboring farmers ${ }^{8}$ for any damaged sustained from lower groundwater tables (Interviewee 3, 2009). This approach to the use of water resources has characteristics of 'weak sustainability' conceptualizations, as it is anthropocentric and narrowly/locally focused, rather than holistic and integrative of socio-ecological systems (van der Bergh et al. 2007).

The operationalization of the chosen sustainability criteria is narrow, resulting in the conclusion that groundwater is the only resource that satisfies all these criteria (WRD 2000, 5; Interviewee 3, 2009). Regarding security of supply, Vitens argues that the smaller the distance between extraction and consumption sites, the more secure drinking water production is. Surface waters are viewed as undesirable, because eventual sources are farther away from Wierden and surrounding clients, and because of summer draught risks, requiring additional (costly) water storage infrastructure. The criterion of safeguarding human health is operationalized as 'the lowest risk to human health.' Surface waters are easily dismissed as unreliable chemically and bacteriologically (Interviewee 3, 2009). During GGOR meetings, WRD pointed to the safe use of surface waters in the densely populated western part of the country and abroad (Interviewee 4, 2009). Vitens invoked the company's culture and tradition in using groundwater, which need also consideration, as sustainability dimensions (Interviewee 3, 2009).

Another narrow operationalization is that of the environmental criterion. Nature impacts are not considered as part of the environmental criterion, but are viewed as being part of the 'good neighboring relations' social objective the company (Vitens 2002). Only two environmental impacts are considered important: greenhouse gas emissions and wastes' generation in purification processes (Interviewee 3, 2009). Vitens argues that, as groundwater needs less purification efforts, it consumes less electricity and generates less wastes. Nevertheless, Vitens states on its Web site that its electricity comes $100 \%$ from renewable resources, while purification wastes are fully recycled/reused ${ }^{9}$.

\footnotetext{
${ }^{7}$ Letters between PCO, the Nature Minister and European authorities are available at PCO's Web site (http://www.overijssel.nl).

8 Around Wierdense-Veld farmers have been financially compensated by Vitens for decreased agricultural output, based on national legislation (TAUW 2009, 104).

9 Sources: http://www.vitens.nl/overvitens/water/Paginas/Reststoffen.aspx and http://www.vitens.nl/over vitens/water/Paginas/Visie-op-duurzaam.aspx (20-10-2012).
} 
The quality of surrounding nature areas is not incorporated in the sustainability operationalization. Besides, Vitens does not value the Wierdense-Veld much (Owens 2008, 98-99), considering that its habitats do not deserve Natura-2000 (Interviewee 3, 2009). It was suggested that nature areas south of Wierden are more valuable (though they have an inferior legal protection status, which is ecologically established), and parts of them would be affected if more than $2 \mathrm{Mm}^{3} /$ year of its Pump-I production are moved there (the latter being supported by the Environmental Impacts Study, TAUW 2009, 91-114). Vitens' boundary judgments on terrestrial ecosystems draw also on weak sustainability conceptualizations, where habitats of different types may be traded-off or abandoned for human needs.

It is striking that the operationalization of the first three sustainability criteria is in support of the former: minimizing consumer costs for drinking water (Vitens 2002). As a commercial company Vitens, primary motivations behind its 'action' (see Fig. 1) preferences are profitability and cost minimization. However, the consumer costs for drinking water in Overijssel are among the smallest in Europe, with only 80 Eurocents $/ \mathrm{m}^{3}$, while drinking water supply to households is a monopoly (Interviewee 4, 2009). It is, therefore, useful to understand how these boundary judgments on water resources' use and terrestrial ecosystems are shaped through regulations and policy frameworks.

Figure 1 suggests that constraining mechanisms can affect actors' institutional freedom to define sustainable development. A content analysis of legislation indicates that Vitens benefited for long of large institutional freedoms to define sustainability, based on the following key legal instruments: Drinking Water Directive 98/83/EG; Groundwater Directive 2006/118/EG; the 2001 National Water Infrastructure Order. There are no legislative constraints/requirements concerning the types of water resources to be used for drinking water production, the sustainability criteria to be applied and their operationalization. Nevertheless, Vitens cannot operate without a PCO permit, and the PCO's official policies prioritized the same sustainability criteria and operationalizations for decades as Vitens.

E.g., PCO's 2008 policy document 'Regional Vision' considered that: 'Drinking water extraction should be sustainably located and exploited. This means that next to a good protection against pollution, the negative impact on the natural water system should be as small as possible, and the damage to the (land) functions of agriculture and nature should be minimized. Besides, we are committed to an environmentally responsible (use of wastebased electricity, low energy consumption) and techno-economically responsible (low costs, security of supply) production style.' (PCO 2008, 108). Although nature dehydration impacts are acknowledged, PCO considers that a trade-off is worthwhile, given the water quality and security of supply benefits of groundwater (PCO 2008, 107). Similar positions can be found in PCO's spatial planning and nature management policy documents, all sharing a 'weak sustainability' approach to development. Hence, regional policy frameworks operated as constraining mechanisms for Vitens, restricting its national and European institutional freedom to operationalize sustainability and shaping its boundary judgments on what represents a sustainable use of waters as natural resources. PCO never had to use its permitting competence directly, as constraining mechanism for Vitens' use of groundwater, as suggested by the vertical downwards arrow in Fig. 1. Vitens has embraced PCO's boundary judgments on water resources entirely (Interviewee 3, 2009), being aware that its institutional space for sustainability operationalizations is shaped regionally; only national and European legislation can change that or a shift in PCO's political profile through provincial elections.

It would not be adequate to consider PCO's influence as persuasion mechanism, as there has never been such a persuasive/interaction process. Vitens and its predecessors used 
groundwater long before the sustainability concept was introduced in policy/legal frameworks, in the 1970s-1980s. As PCO acquired (nationally- and European-imposed) legal responsibilities for regional sustainable development, it had to clarify how it implements the concept across its competence areas, including water management. As its boundary judgments regarding water resources use emerged, stated in official documents, Vitens adopted them. In this context, the GGOR persuasive mechanism failed to persuade Vitens to cease its groundwater extraction around Wierdense-Veld for habitat restoration and switch to surface water use (Interviewees 1,2,3,4, 2009). The interviewed company representative acknowledged that the many technical studies discussed during the meetings, and the facilitated exposure to other actors' perceptions, values and priorities did not produce motivational or knowledge changes among the company's decision-makers; there were no changes in the hierarchy of interests, values, attitudes, perceptions, while most studies reiterated previously available knowledge.

Owens (2008, 98-99) also documents that Vitens entered the GGOR process with openness toward the idea of removing $2 \mathrm{Mm}^{3} /$ year from Pump-I. However, whenever it was asked to remove $4 \mathrm{Mm}^{3} /$ year from Pump-I, rather than $2 \mathrm{Mm}^{3} /$ year, Vitens threatened to abandon the GGOR process (Owens 2008, 94-107). By 2004, Vitens approached PCO with a request to commission an Environmental Impact Assessment for a new extraction site south of Wierden, to relocate $2 \mathrm{Mm}^{3} /$ year of its extraction at Pump-I. This 'action change' (see Fig. 1) was exclusively the result of the three constraining mechanisms explained above (TAUW 2009, 9), of which 'the plan to build a road was decisive' (Water Taskforce 2012, 25; also TAUW 2009, 106). The dehydration reduction was considered a 'nice side effect' (Owens 2008, 103). The new permit was issued in 2010, though by 2012 physical works were still to begin (Water Taskforce 2012, 26).

The company is still negatively motivated regarding the removal of additional $2 \mathrm{Mm}^{3}$ / year from Pump-I (Interviewee 3, 2009; TAUW 2009, 13). This negative motivation is sustained by PCO's unchanging boundary judgments and behavior. By November 2012, the PCO's Web site indicated that PCO was still working on a Management Plan for Wierdense-Veld, as required under the Natura-2000 and Water Framework Directives (while countrywide and in Overijssel, most reserves had plans under implementation). Stakeholders cannot take legal action against Vitens, unless there is such plan, requiring Vitens to implement adequate measures to safeguard the habitat objectives. The removal of additional $2 \mathrm{Mm}^{3} /$ year is important only for the complementary objective of peat habitat restoration, for which national/sub-national authorities are not responsible in Brussels (Arcadis 2008, 41). Consequently, it is unlikely that PCO's pending Management Plan or the Water Framework Directive will operate as constraining mechanisms for Vitens to remove the additional $2 \mathrm{Mm}^{3} /$ year of drinking water production (affecting its powers, though permits, as suggested through the vertical arrow in Fig. 1).

\subsection{The impact of convergence mechanisms on farmers}

The 22 farms involved in the GGOR-East process are predominantly animal farms, while some specialize in cropping. Most farmers practice intensive agriculture and none engages in organic farming (Arcadis 2008, 46). As commercial agents, their main motivations are cost efficiency and profitability; they do not have to have an explicit, formal sustainability conceptualization, like PCO or a public company. As mentioned earlier, no interviews were carried out with farmers regarding their boundary judgments on sustainability and natural resources, which is a limitation of this case study. What can be argued, however, is that their 'behavior' (agricultural practices, business size) is constrained by the 
environmental legislation (European/national/sub-national) regarding emissions from their farms (e.g., ammonia, nutrient leaching) and other provisions in their operation permits issued by PCO (relationships captured by the vertical downwards arrow from constraining mechanisms, in Fig. 1).

In a PCO study, one farmer mentioned that in 2000 , all farms were positively motivated toward finding a solution for Wierdense-Veld (PCO 2007, 74; endorsed by Interviewees 1 and 2, 2009). During the GGOR process, LO and WRD agreed to take responsibility for several infrastructural and ecological measures within the reserve. They also pledged support for farmers to implement water retention measures in summer, to lift groundwater tables. Farmers were also asked to change their practices and abstain from water drainage, which sometimes was inadvertent (like taking heavy equipment in the field early in the spring, when soils where still water saturated, contributing to drainage; Owens 2008, 94-101).

Initially, farmers were scared of increases in groundwater tables (Interviewee 1, 2009). However, the GGOR process was exceptionally successful at persuading farmers to accept many such measures, improving their hydrological, ecological, even agricultural knowledge of the area (PCO 2007, 75; Interviewee 2, 2009). The DLV, WRD and LO experts demonstrated that the economic damage of summer draught for agriculture is higher than the damage due to temporarily higher groundwater tables in winter. The finding that groundwater table increases are profitable for agriculture, on an annual basis, was a 'culture shock for farmers' (Owens 2008, 101). A key contributing factor to the acceptance of this new information was that DLV and WRD have traditionally had a strong trusting relationship with farmers in Overijssel (Owens 2008, 101). DLV was actually, formerly, a farmers' association, while WRD is politically elected, allocating special seats for farmers. Knowledge improvements resulted in reshufflings of farmers' hierarchies of perceived interests and values, hence motivational changes (Interviewee 4, 2009). An enabling mechanism was also indicated as possibly available for the costs incurred by farmers toward water retention. The Provincial Multi-annual Program contains a financial instrument that might offer them funding for implementation (Arcadis 2008, 32-33). This further contributed to positive motivations, creating support even among the more skeptical farmers (Interviewees 1 and 2, 2009).

Nevertheless, the successful persuasion mechanism and the potentially available enabling mechanism have not led so far to any 'action changes.' GGOR discussions started to be affected, around 2004, by concerns regarding the consequences of Natura-2000 legislation for the future of farming. GGOR was meant to be a stand-alone process, supporting the implementation of the Water Framework Directive, which required integrated water management that supports, among others, nature protection. However, the same farmers were target groups for the Natura-2000 legislation. Of strong concern was the stricter environmental ammonia standards envisaged, which also blocked the growth opportunity of at least twelve animal farms (Arcadis 2008, 46-51). As the political arena was signaling that PCO's efforts to reverse the Natura-2000 listing of Wierdense-Veld were unlikely to be successful, farmers' motivations were experiencing a negative change (two anonymous farmers in PCO 2007, 74-75; also Arcadis 2008, 38-39). This is unfortunate in the particular case of Wierdense-Veld, where nature suffers mostly of dehydration, not of ammonia pollution (PCO 2007, 74-75).

Given farmers' attitude change and refusal to cooperate for combating dehydration, in 2006, PCO 'temporarily interrupted' the GGOR-East process, invoking uncertainties regarding the wetland's Natura-2000 status (Arcadis 2008, 30). The process did not restart after Wierdense-Veld's definitive listing in 2009. While farmers are unlikely to be sued 
based on the Water Framework Directive, because the accountability system is less straightforward, they could be sued by LO or the Nature Minister for failing to implement measures that are essential for achieving the three primary goals of Natura-2000. But this can only happen if PCO agrees to incorporate measures under farmers' responsibility in the expected Management Plan for Wierdense-Veld. If PCO's plan is itself inadequate, PCO may be sued before national/European justice courts, by nature stakeholders.

\section{Concluding reflections and suggestions for further research}

The application of the behavioral theoretical framework proposed in this paper to the case study reveals some important findings. These are mapped in Fig. 3, which is an application of the Fig. 1 framework for Vitens' behavioral change. First, the boundary judgments of the water company Vitens on water resources and terrestrial ecosystems have been so far influenced most strongly by: (a) conceptualizations of weak sustainability that have been narrowly operationalized and (b) motivations to minimize consumer costs for drinking water; these boundary judgments have emerged in the context where (c) Vitens' institutional freedom for operationalizing sustainability was large, de juro, up to 2009-2012 (based on European and national legislation), but was constrained, de-facto, by the provincial authority, becoming rather small. The analysis revealed that, in such contexts, it would be ineffective to try to stimulate an actor's 'action change' (e.g., change of

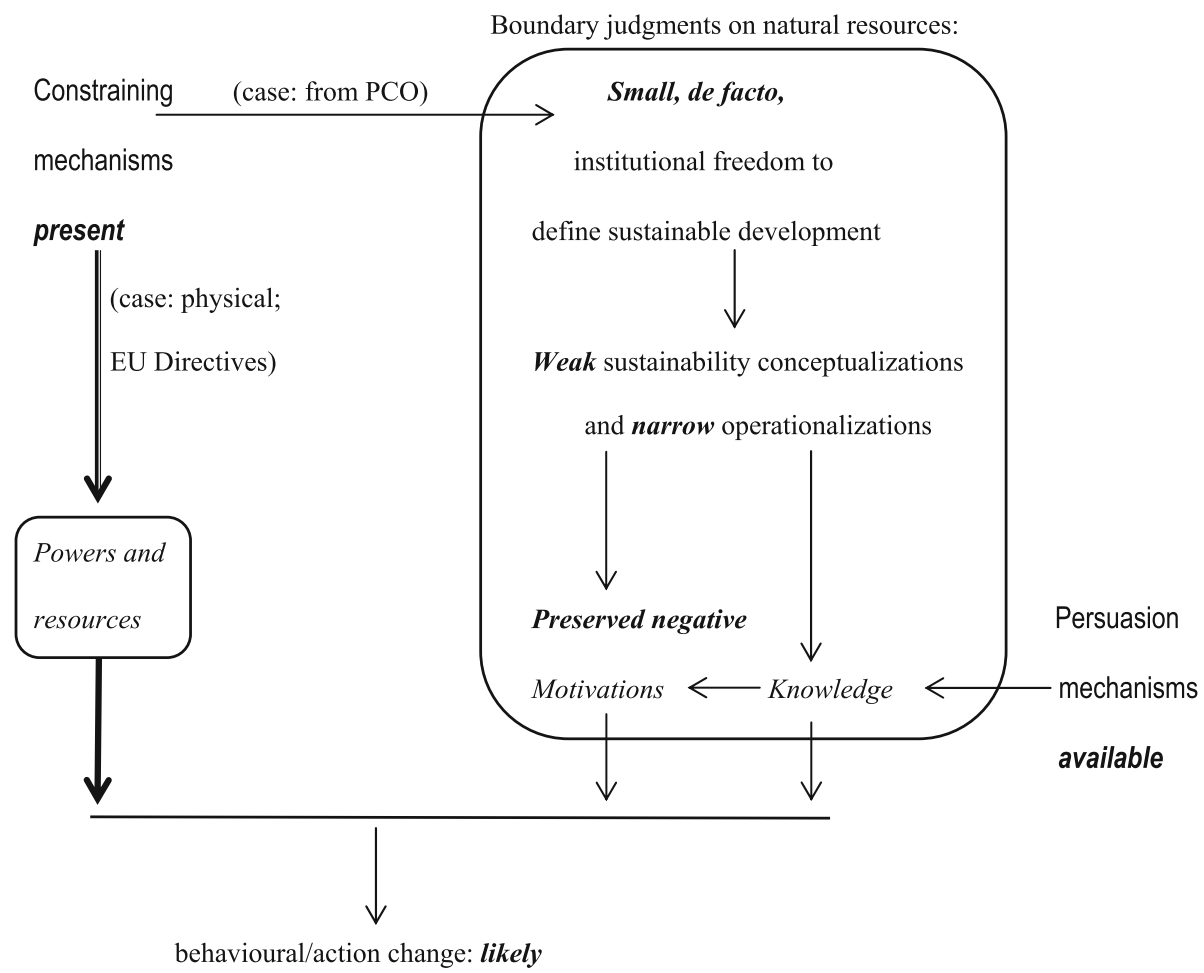

Fig. 3 Hypothesis drawing on Vitens behavioral change in the Wierdense-Veld case study 
operations or strategy) through persuasion mechanisms and that constraining mechanisms are more desirable. Consequently, drawing on this case study, the author would like to formulate the following hypothesis (represented in Fig. 3), for further testing on key actors involved in conflicts on natural resources use: Constraining mechanisms are likely to be more effective then persuasion mechanisms, when:

- the institutional freedom for defining sustainability of the concerned actor is in practice small/limited;

- the actors holds weak conceptualizations of sustainability and/or narrow operationalizations;

- the actor has negative motivations toward behavioral change and

- enabling mechanisms are not available.

In Vitens' case, if the physical constraining mechanisms did not emerge, its 'behavioral change' could only have been expected through the implementation of the Natura-2000 and Water Framework Directives; but it is unclear when, since PCO's Natura-2000 Management Plan was still awaited in November 2012. Another interesting question for further research is whether, under similar circumstances, enabling mechanisms would generate different action choices, and how. In this case, they were not available for Vitens.

Secondly, the proposed framework was also helpful toward understanding farmers' behaviors, as result of various convergence mechanisms. Empirical analyses suggest thatin the context of large institutional freedoms for the conceptualization of sustainabilitypersuasion mechanisms may lead to behavioral/action changes; however, for this to occur persuasion mechanisms should be able to generate not only new knowledge, but also positive motivations for the respective actor. Enabling mechanisms may help, in such cases, to generate/consolidate positive motivations toward behavioral/action change. This empirical finding is represented in Fig. 4, which can be viewed as another hypothesis based on this framework, worth testing in other case studies. Further, the Dutch case study suggested that involvement of trusted actors in the persuasion mechanisms may be, in some cases, more important than the direct involvement of scientists, even when the same technical information is presented and discussed. This may happen when scientists have a modest/poor track record (in the respective community) of conducting and/or communicating their research, in ways that are perceived as unbiased by lay people.

Another lesson is that convergence mechanisms for behavioral/action change should ideally consider an actor's situation more holistically, as he will be targeted for behavioral/ action change under a wide range of legal/policy instruments. Persuasive mechanisms for the implementation of the Water Framework Directive by farmers were not accompanied by persuasive and/or enabling mechanisms (e.g., financial compensations) for the impending implementation of the Natura-2000 legislation. This compromised the effectiveness of the GGOR persuasive mechanism. It is also important to keep in mind that although enabling mechanisms might generate/strengthen positive motivations toward behavioral change, it may still be difficult to sustain such new behavior beyond the point where they cease to bring immediate individual benefits that are comparable to past benefits. Long-lasting behavioral changes (with the acceptance of lower economic individual benefits) may only be expected if persuasion and/or constraining mechanisms are able to change an actor's boundary judgments regarding natural resources and sustainability so that he considers environmental quality as a valuable societal asset, worth preserving long into the future. In addition to the above-suggested hypotheses for further testing, the theoretical framework lends itself to the development of other hypotheses. Through large number empirical testing, these may form the basis for new strategies of 


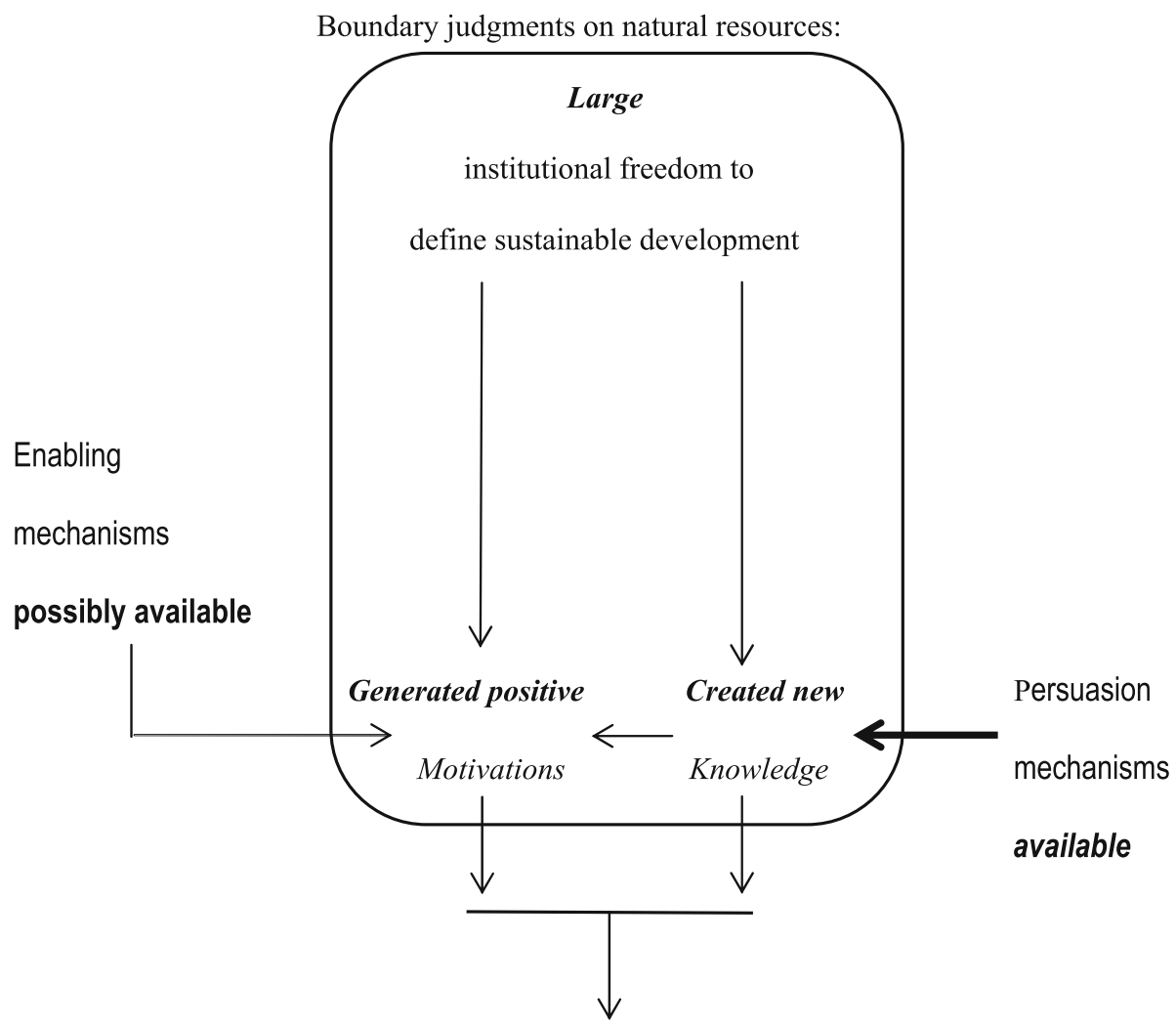

behavioural/action change: likely

Fig. 4 Hypothesis drawing on farmers' behavioral change (before the Nature 2000 listing of WierdenseVeld, resulting in the stalling of the GGOR process)

intervention in conflicts on natural resources use for sustainable development. The author encourages further theoretical and empirical work based on the framework proposed in this paper.

In terms of practical utility, an early application of this theoretical framework by the Nature Ministry for the analysis of how habitat objectives could be achieved at WierdenseVeld (e.g., in 2002-2003) would have led to the following observations:

- three physical constraining mechanisms influenced Vitens to move $2 \mathrm{Mm}^{3} /$ year of drinking water production from Pump-I, lifting groundwater tables by $9 \mathrm{~cm}$ (TAUW 2009, 101);

- following the GGOR persuasive mechanism, farmers were willing to cooperate, resulting perhaps in up to $40 \mathrm{~cm}$ groundwater levels increase, especially if enabling mechanisms were made available;

- LO and WRD were willing to implement measures, lifting groundwater tables by $10 \mathrm{~cm}$.

All these efforts would have helped significantly toward implementation of the three primary habitat objectives associated now with Natura-2000. Currently, due to regional 
opposition, the peat habitat objective was downgraded to 'complementary,' and target groups cannot be constrained to achieve it under Natura-2000 legislation.

An early application of this framework would have also indicated that a long-term nationwide solution for the nature dehydration problem due to water companies' operations can be best tackled by means of national/European legislation reducing the institutional freedom of provincial/permitting authorities and water companies to conceptualize and operationalize sustainability, by requiring more holistic approaches for water and nature management, that incorporate clear nature quality outcomes. ${ }^{10}$ Consequently, the application of this framework suggests that the listing of Wierdense-Veld as Natura-2000 site was not really necessary for the achievement of the three primary habitat objectives. However, countrywide, Natura-2000 legislation is needed. It is expected to generate action changes among water companies toward better nature protection and, perhaps, in long term, even wider boundary judgments regarding the role of ecosystems in the sustainable development of societies.

Open Access This article is distributed under the terms of the Creative Commons Attribution License which permits any use, distribution, and reproduction in any medium, provided the original author(s) and the source are credited.

\section{References}

Allen, M., \& Preiss, R. W. (Eds.). (1998). Persuasion: Advances through meta-analysis. Cresskill, NJ: Hampton.

Arcadis. (2008). Classification of Wierdense-Veld as Natura-2000 area: Appropriate or not? Financeable or not? Zwolle.

Bressers, H. (2006). Implementing sustainable development: how to know what works, where, when and how. In W. M. Lafferty (Ed.), Governance for sustainable development (pp. 284-318). Cheltenham: Edward Elgar.

Bressers, H., \& Lulofs, K. (Eds.). (2010). Governance and complexity in water management, creating cooperation through boundary spanning. Cheltenham: Edward Elgar/IWA.

Cabeza-Gutés, M. (1996). The concept of weak sustainability. Ecological Economics, 17, 147-156.

Cialdini, R. B. (2007). Influence: The psychology of persuasion. New York: HarperCollins Publishers.

DellaVigna, S., \& Gentzko, M. (2010). Persuasion: Empirical evidence. The Annual Review of Economics, 2, 643-669.

Dillard, J. P., \& Pfau, M. (2002). The persuasion handbook: Developments in theory and practice. Thousand Oaks, CA: Sage Publications.

Dinica, V. (2009). Sustainable development and groundwater use: the role of boundary judgments, institutional objectives and convergence mechanism in Overijssel, Netherlands. Deliverable to the EU Project 043199 Integrative Systems and the Boundary Problem. Report presented at the Annual Workshop EU-ISBP in Castellaneta Marina, Bari, Italy, June 15-17, 2009. Enschede: CSTM, University Twente, CSTM Series Studies and Reports Nr 340. ISSN 1381-6357, pp. 1-153.

DLV. (2002). Final report on water management for Hooge Laarsleiding and the interactive application of the GGOR approach. Dronten.

Gazzaniga, M. S., \& Heatherton, T. F. (2003). Mind, brain and behavior: Psychological science. New York: Norton \& Company Inc.

Kahneman, D. (2012). Thinking, fast and slow. London: Penguin Books.

KIWA. (2007). Natura-2000 Wierdense-Veld. Nieuwegein.

Klok, P. J. (1991). An instrument theory for environmental policy. Enschede: University of Twente.

\footnotetext{
${ }^{10}$ Vitens extracts groundwater and in many provinces and contributes to nature dehydration in many nature areas. Numerous reports indicate many Dutch water companies extracting groundwater share similar boundary judgments and behavioral influences (Water Taskforce 2012; Owens 2008; PCO 2007).
} 
Lockton, D., Harrison, D., Holley, T., \& Stanton, N. A. (2009). Influencing interaction: Development of the design with intent method. In Proceedings of fourth international conference on persuasive technology, Claremont US, April 26-29, 2009.

Ostrom, E. (1987). An agenda for the study of institutions. Public Choice, 48(1), 3-25.

Owens, K. A. (2008). Understanding how actors influence policy implementation: A comparative study of wetland restorations in New Jersey, Oregon, The Netherlands and Finland. The Netherlands: Twente University Press.

PCO. (2007). Decision for the denomination of Natura-2000: Summary of submission. Zwolle.

PCO. (2008). Change to the ordinance for spatial planning overijssel. Policy document adopted in May 2008. Zwolle (in Dutch).

Sabatier, P. A., \& Jenkins-Smith, H. C. (1999). The advocacy coalition framework: An assessment. In F. Sabatier (Ed.), Theories of the policy process (pp. 117-168). Boulder, CO: Westview Press.

Seiter, R. H., \& Gass, J. S. (2010). Persuasion, social influence, and compliance gaining. Boston: Allyn \& Bacon.

Solow, R. M. (1986). On the intergenerational allocation of natural resources. Scandinavian Journal of Economics, 88(1), 141-149.

Spillane, J. P., Reiser, R. P., \& Reimer, T. (2002). Policy implementation and cognition: Reframing and refocusing implementation research. Review of Educational Research, 72(3), 387-431.

TAUW. (2009). Environmental impact assessment for the partial relocation of groundwater Wierden. Zwolle.

TNO. (1994). Optimization of water management at Wierden/Wierdense-Veld. TNO-Rapport 94-36 B. Oosterwoolde.

Tomassen, H., van Duinen, G. J., Smolders, F., Brouwer, E., van der Schaaf, S., van Wirdum, G., et al. (2005). Preliminary research on Wierdense-Veld. Nijmegen: Radboud University Nijmegen.

Ulrich, W. (1987). Critical heuristics of social systems design. European Journal of Operational Research, 31(3), 276-283.

Ulrich, W. (2002). A brief introduction to critical systems heuristics. In H. G. Daellenbach \& R. L. Flood (Eds.), The informed student guide to management science. London: Thomson Learning.

Ulrich, W., \& Reynolds, M. (2010). Critical systems heuristics. In M. Reynolds \& S. Holwell (Eds.), Systems approaches to managing change: A practical guide (pp. 243-292). London: Springer.

van den Bergh, J., Atkinson, G., Dietz, S., \& Neumayer, E. (2007). Handbook of sustainable development. Cheltenham: Edward Elgar.

Verburg, G. [Minister for Nature Agriculture and Fisheries]. (2008). Update on Natura-2000. Letter to the President of the Second Parliament Chamber No. PDN.2008/3491. 22-08-2008. The Hague.

Vitens. (2002). Environmental impact assessment for drinking-water supply in North-East Twente. Zwolle.

Warner, J., Lulofs, K., \& Bressers, H. (2010). The fine art of boundary spanning: Making space for water in the East Netherlands. Water Alternatives, 3(1), 137-153.

Water Taskforce. (2012). The power of water. Report to the Ministry for Infrastructure and Environment. The Hague.

WMO. (2000). Water production: a vision on sustainable drinking-water extraction in Overijssel. Version 4.0. Zwolle.

WRD. (2000). Drinking water production in Twente in a sustainable perspective. Almelo.

Warner, J., Lulofs, K., \& Bressers, H. (2010). The fine art of boundary spanning: Making space for water in the East Netherlands. Water Alternatives, 3(1), 137-153. 